\title{
Spontaneous Uterine Rupture during Pregnancy: Case Report and Review of Literature
}

\author{
E. Nkwabong', L.Kouam ${ }^{2}$ W. Takang ${ }^{3}$
}

\begin{abstract}
Rupture of a gravid uterus is a surgical emergency. Predisposing factors include a scarred uterus. Spontaneous rupture of an unscarred uterus during pregnancy is a rare occurrence. We hereby present the case of a spontaneous complete uterine rupture at a gestational age of 34 weeks in a 35 year old patient. The case was managed at the University Teaching Hospital of Yaounde (Cameroon). She had past history of two uterine curettages. She presented with abdominal pain of sudden onset. After ultrasound scan, uterine rupture was diagnosed and an emergency laparotomy done. The entire amniotic sac was found in the peritoneal cavity with a rupture of the uterine fundus. Spontaneous uterine rupture occurs when there is an upper segment uterine scar. This case report shows that past history of curettage is a risk factor for the presence of uterine scar. (Afr J Reprod Health 2007; 11[2]:98-103).
\end{abstract}

\section{RÉSUMÉ}

Rupture spontanée de l'utérin pendant la grossesse: rapport du cas et bilan de la documentation La rupture d'un uterus gravid est une urgence chirurgicale. Les facteurs de prédisposition comprennent un utérin cicatriciel. La rupture spontannée d'un utérin non-cicatriciel pendant la grossesse est rare. Nous présentons ici un cas d'une rupture complète et spontanée de l'utérin à un âge gestationnel de 34 semaines chez une patiente de 35 ans. Le cas a été pris en charge au Centre Hospitalier Universitaire de Yaounde (Cameroun). Elle avait un antécédent de deux curettages de l'utérin. Lorsqu'elle s'était présentée pour la première fois, elle souffrait d'une douleur abdominale qui avait commencé soudain. Après avoir une échographie, nous avons diagnostiqué une rupture de l'utérin et une laparotomie d'urgence a été faite. La cavité amniotique entière se trouvait dans la cavité péritonéale avec une rupture du fond de l'utérus. La rupture spontanée de l'utérin se produit quand il y a une cicatrice du segment supérieur de l'utérin. Ce rapport de cas montre que les curettages comme antécédents constituent un facteur de risque quant à la présence de la cicatrice de l’utérin. (Rev Afr Santé Reprod 2007; 11[2]:98-103).

KEY Words: Past history of curettage, Pregnancy, Spontaneous uterine rupture

${ }^{1}$ Obstetrician \& Gynecologist, Obstetrics and Gynecology Service; University Teaching Hospital Yaounde, Cameroon. P.O.Box 11063 Yaounde, Email: enkwabong@yahoo.fr

${ }^{2}$ Obstetrician \& Gynecologist, Department of Obstetrics and Gynaecology; Faculty of Medicine and Biomedical Sciences/ University Teaching Hospital Yaounde,

${ }^{3}$ Obstetrician \& Gynecologist, Obstetrics and Gynecology Service; University Teaching Hospital Yaounde, Cameroon 


\section{Introduction}

Ruptured uterus is an obstetric and surgical emergency that can lead to maternal or fetal death. The maternal and fetal prognoses are most of the time bad especially if rupture occured in an unscarred uterus ${ }^{1,2}$. Uterine rupture happens usually during delivery. The causes include misuse of oxytocic drugs, obstetrical maneuvers especially if it was on a scarred uterus ${ }^{3}$. Uterine rupture can also occur, though rarely, during pregnancy, notably if the patient had a uterine scar on the upper uterine segment (corpus) as the case of patients who have had a previous uterine rupture, classical caesarean section or uterine perforation ${ }^{4}$. Spontaneous rupture of an unscarred uterus is very rare. We hereby report a case of spontaneous uterine rupture at 33 weeks and 4 days of gestation in a patient who has never had a previous uterine surgery, but who has had uterine curettage twice for missed abortion.

\section{Case Report}

Mrs K.E. was 35 years old and married. Her last menstrual period was on February 10, 2006. At presentation on the $3^{\text {rd }}$ of October 2006 she was gravida 7 para 4 with a gestational age of 33 weeks 4 days. Her blood group is A rhesus positive. The pregnancy was monitored in a district hospital where an ultrasound scan done at the $20^{\text {th }}$ week of gestation showed an intrauterine normal pregnancy. She presented at the University Teaching Hospital of Yaounde (Cameroon) with complaints of fatigue and abdominal pains that started 2 days prior to consultation. The abdominal pain was initially located in the pelvis and became generalized in the whole abdomen on the following day, associated with severe fatigue. She has had 4 full term pregnancies which all ended in normal delivery. The birth weights ranged between 2900 and 3200g. The last 2 pregnancies in 2003 and

Empty uterus with little blood in the uterine cavity Site of uterine rupture located at the fundus

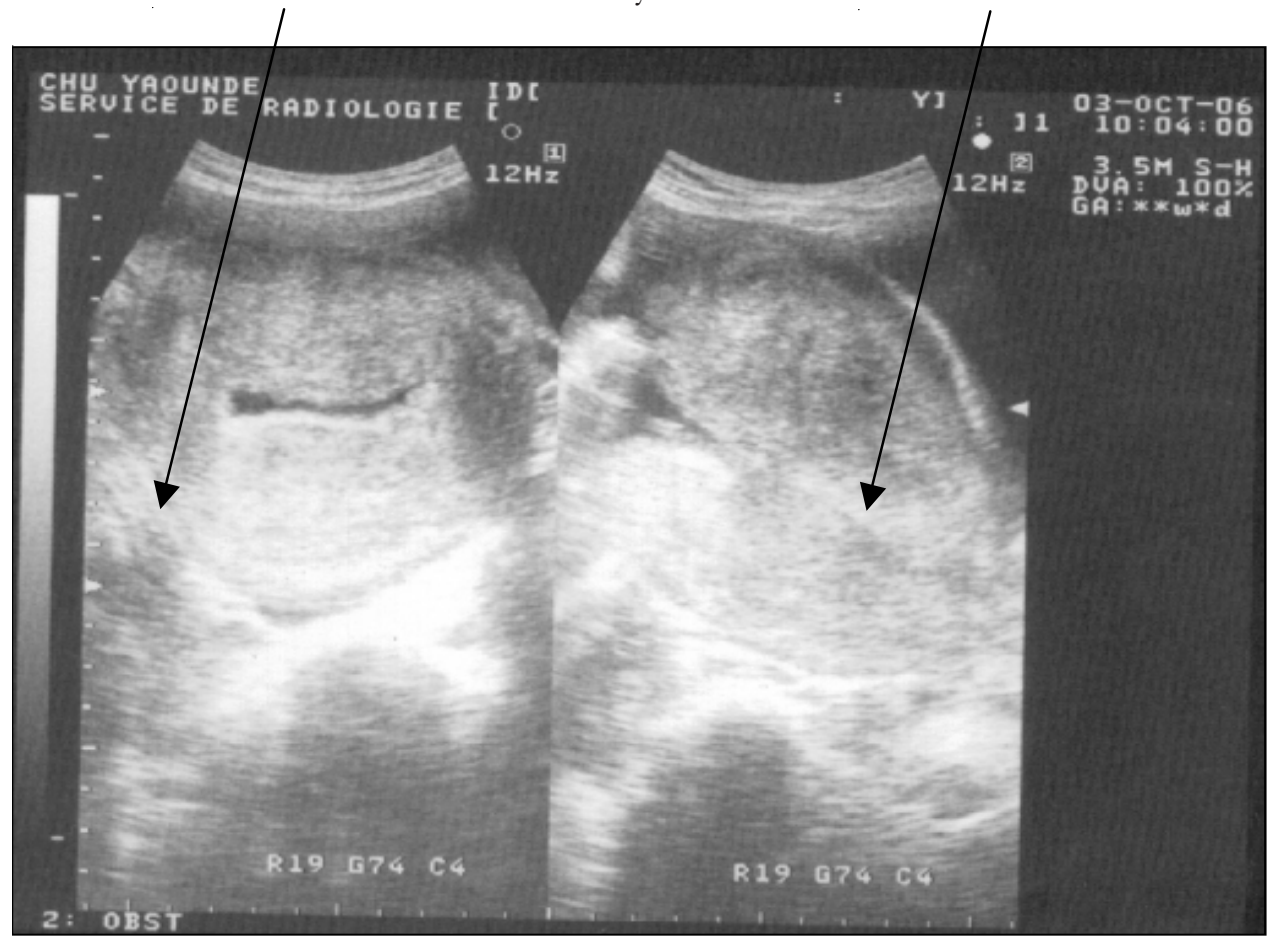

Picture 1: ultrasound scan diagnosis of uterine rupture 
2004 ended in missed abortions at 11 and 15 weeks of gestation and curettage was done with normal follow-up treatment.

On physical examination, her general state was bad. Her blood pressure was 120/70 mmHg, and the pulse was 124 beats/min. The conjunctivae were pale. The abdomen was distended and tender. The fetus was in tranverse lie with the head easily palpated at the right flank. The fetal heart beat was absent. A diagnosis of ruptured abdominal pregnancy was made and an emergency ultrasound scan was done. It revealed an empty uterus which had a tear at the fundus (picture 1). The fetus was in the abdominal cavity in transverse lie with no heart beat. Fetal measurements revealed a 34 weeks old pregnancy.

The final diagnosis was ruptured uterus at 33 weeks and 4 days gestation. An emergency laparatomy was done. Preoperative hemoglobin level was $8.4 \mathrm{~g} / \mathrm{dl}$. Under general anesthesia and antibiotic coverage (ceftriaxone), a mid line sub umbilical incision was made. As findings there was an intact sac of amniotic fluid containing a fetus and the placenta in the abdominal cavity above the uterine fundus (picture 2). There was hemoperitoneum made up of altered blood. After removal of the amniotic sac from the abdominal cavity and suction of the haemoperitoneum of about $1500 \mathrm{cc}$, the uterus was about 16 weeks pregnant and had at the fundus a tear of about $7 \mathrm{~cm}$ with little bleeding (picture 3 ). The uterus was sutured in 2 layers with Vicryl ${ }^{\mathbb{B}}$ $\mathrm{n}^{\circ} 1$ and bilateral tubal ligation was done using the Pomeroy technique. During surgery $500 \mathrm{ml}$ of whole blood group A rhesus positive was transfused to the patient, and another $500 \mathrm{ml}$ was tranfused after surgery. When the amniotic sac was opened later, there was a still birth female fetus that weighted $1844 \mathrm{~g}$ with placental tissue and fetal membranes weighing $425 \mathrm{~g}$.

\section{Picture 2: Intact amniotic sac containing the fetus}

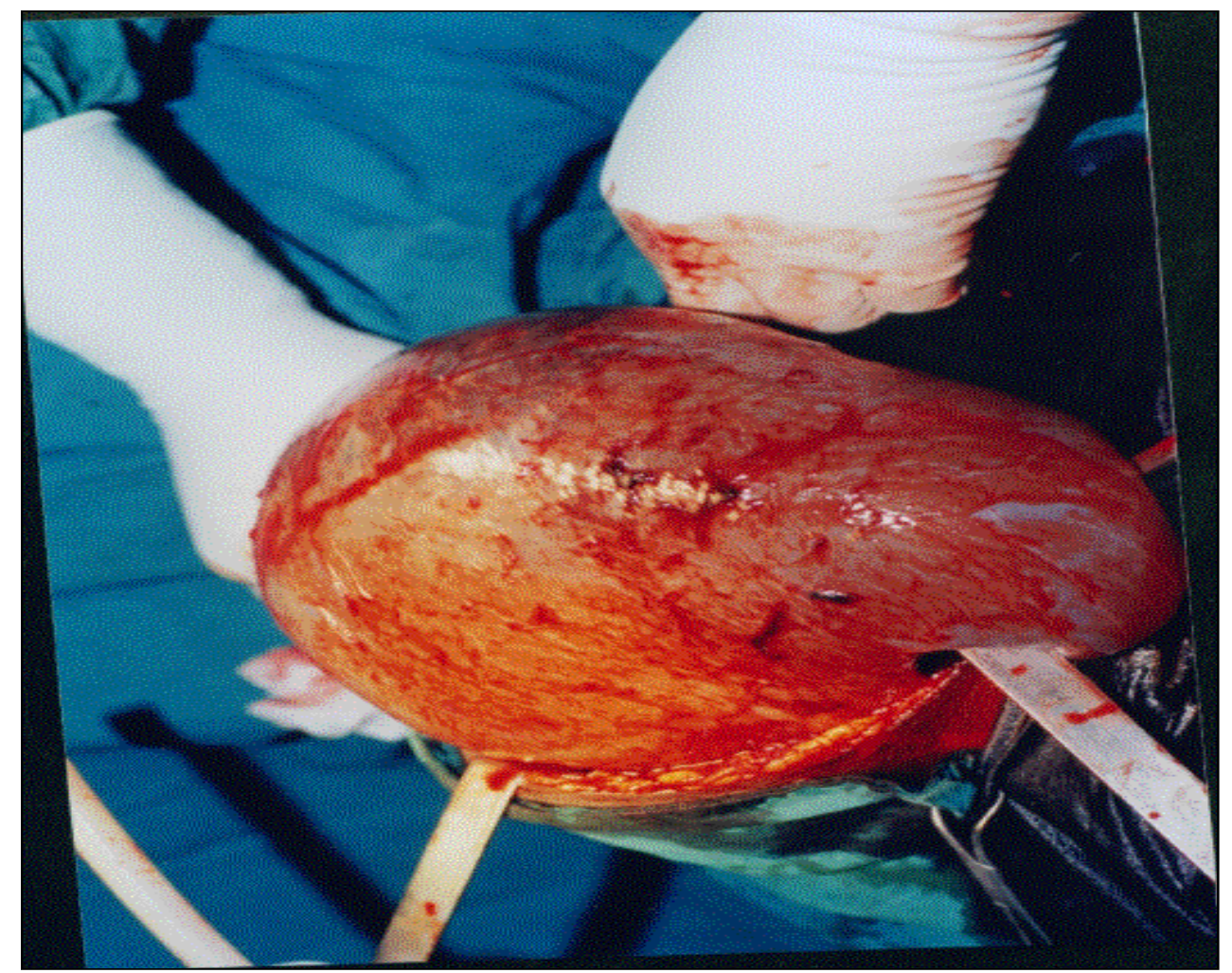

African Journal of Reproductive Health Vol. 11 No.2 August 2007 
Picture 3: uterine rupture discovered per operatively

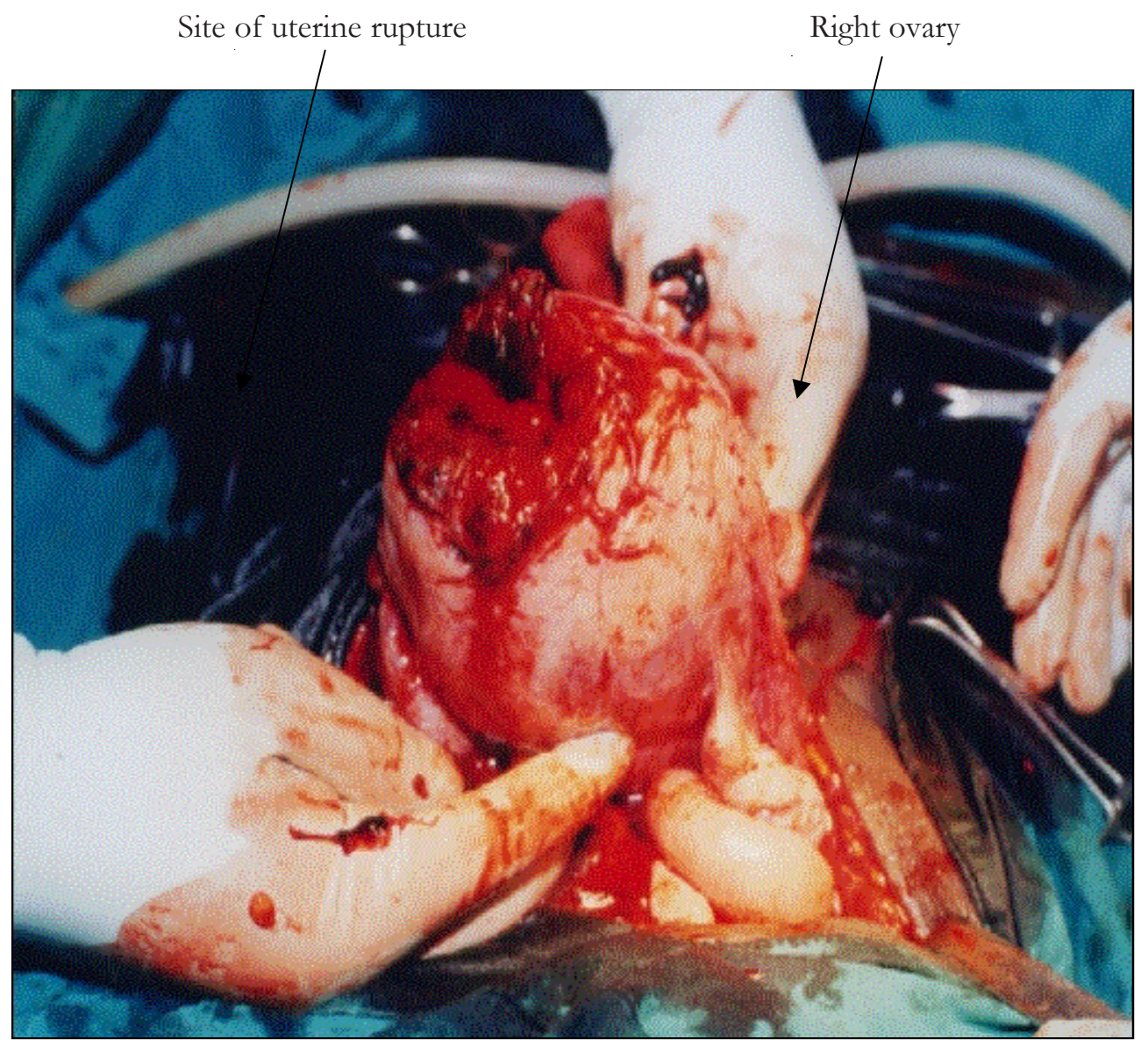

Post operative management was without complications. Post operative haemoglobin was $10.4 \mathrm{~g} / \mathrm{dl}$ and the patient was discharged from the hospital 8 days after surgery.

\section{Comments:}

Rupture of a gravid uterus is one of the worst obstetric emergencies in which the life of both the mother and the child are in danger. The incidence ranges from between 0.2 to $0.6 \%$. Factors that can predispose to uterine rupture are multiparity, advanced maternal age, a scarred uterus, a big fetus, mal presentation, a contracted pelvis, the misuse of oxytocic drugs, obstetrical maneuvers like external cephalic or internal podalic version, instrumental deliveries ${ }^{2,3}$. Uterine rupture can also occur without these factors. Manouana et al noticed a case of uterine rupture during labour in which no predisposing factor existed, be it medical, surgical, gynaeco-logical or obstetrical ${ }^{5}$. In our case, the patient was multiparous and she has had 2 previous episodes of uterine curettage for missed abortion. Uterine rupture in multiparity occurs usually during labour. We think that our patient may have had uterine scar from an unnoticed incomplete or complete uterine perforation during curettage. The perforation may have been situated at the uterine fundus and subsequently the products of conception of the current pregnancy may have 
embedded itself in that region, so that when there was continuous distension of the uterus with evolving pregnancy, there was a stretch of the weakened area leading finally to rupture and protrusion of the amniotic sac with the placenta into the peritoneal cavity. This hypothesis has already been made by Bevan et $\mathrm{al}^{6}$.

Our patient was not known to have had a uterine scar, so in her case the diagnosis could have been late. Tannous et al have already noticed a case of uterine rupture in labor after the patient had had hysteroscopy and repeated curettage ${ }^{7}$, but it happened during labor and not before labor as in our case.

Diagnosis of spontaneous uterine rupture during pregnancy occuring on a scarred uterus can be made by ultrasound scan in which case there can be protrusion of membranes at the site of the scar ${ }^{8}$. If possible we should carry on an external electronic fetal monitoring in each case where there is abdominal pain occurring on a pregnancy because in cases of uterine rupture there will be fetal heart rate abnormalities. In the case of late presentation as in our case, there are abdominal pains and signs of shock, at which time ultrasound scan will reveal an intraperitoneal pregnancy. In these cases the fetus is already dead and efforts are made to save the mother.

The incidence of rupture of an unscarred uterus varies between $1 / 8000$ and 1/15 000 pregnancies ${ }^{9,10}$. Most of them occur during labor and can even be due to the application of fundal pressure $^{9}$. Our first diagnosis was not spontaneous uterine rupture. We thought of an abdominal pregnancy not diagnosed by the first ultrasound scan. It was only when we noticed on ultrasonography a uterine tear at the fundus that we thought it was a uterine rupture. This is the first case noticed in our clinic in the past 10 years. Because the medical staff is not always prepared for the eventuality of a uterine rupture when there is no post surgical scar and because of rapid bleeding in case of uterine rupture, the prognosis for both the mother and the child is very bad.
In our case the patient came only 2 days after the onset of pains. We found a dead fetus in the amniotic sac. There was a massive pool of haemoperitoneum of about $1500 \mathrm{ml}$. Since all the products of conception were expelled, the uterus became as small as 16 weeks gravid uterus and this retraction phenomenon reduced the intraperitoneal bleeding so that with time, the patient compensated the blood loss by fluid retention and tachycardia. That is why the blood pressure was normal. We think that if the products of conception were not completely expelled, the uterus may have remained bigger and the bleeding may have become excessive and may have killed the patient. We also think that if the patient came earlier (at the onset of pain), we may have diagnosed fetal heart abnormalities and surgery may have been done earlier, and we may have saved the fetus.

When we opened the peritoneum there was very little bleeding at the site of the uterine rupture. This is because the uterus was retracted and that is why the patient was still alive 1 to 2 days after uterine rupture. Hemoperitoneum was made up of altered blood and we think that the rupture occured 24 to 48 hours before she presented at our clinic, futhermore the fetus was not macerated. The site of the uterine rupture was closed, $500 \mathrm{cc}$ of blood was transfused to the patient per operatively and finally bilateral tubal ligation was done. The patient wanted bilateral tubal ligation because she already had 4 children. Another $500 \mathrm{cc}$ of blood was transfused post operatively. We think that the good evolution of the post operative period was due firstly to the retraction phenomenon of the uterus that limited the intra peritoneal bleeding, secondly to the antibiotic coverage and lastly to the 2 pints blood transfusion.

\section{Conclusion}

Uterine rupture occuring on an unknown scarred uterus is sometimes an unpredictable event. It is associated with very bad maternal and fetal

African Journal of Reproductive Health Vol. 11 No.2 August 2007 
prognosis. Usually it occurs during labor, but as in our case it can sometimes occur during pregnancy. Our case report showed that past history of curettages should be considered as risk factors for uterine rupture even during pregnancy because there could be an unnoticed uterine perforation or uterine weakening by the curettage, notably if it was done in the $2^{\text {nd }}$ trimester because the uterus is softer and thus more fragile. This case report shows that when there is past history of curettage, an abdominal pain occurring on a pregnant uterus should be seriously managed. Ultrasound scan and external electronic fetal monitoring should be carried out rapidly so as to diagnose earlier a uterine rupture.

\section{REFERENCES}

1. Van Der Merwe J.V., Ombelet W.V.A.M. Rupture of the uterus: a changing picture. Arch Gynecol Obstet 1987;240(3):159-171

2. Ahmadi S; Nouira M., Bibi M; Boughi-Zane S., Sadi H., Chaib A. Rupture utérine sur utérus sain gravide. A propos de 28 cas .Gynecol Obstet Fertil $2003 ; 31(9): 713-717$

3. AL Salem M.H., Makhseed M., Ahmed M.A., Gupta M. Rupture of the gravid uterus: experience of the maternity hospital, Kuwait. Med principles pract 2000;9:97-105
4. Enders L.K, Barnhart K. Spontaneous secondtrimester uterine rupture after classical cesarean. Obstet Gynecol 2000; 96:806-808

5. Manouana M., Louis O., Lorgeron P., Pettini R., Lameyred D., Meynieu F. Rupture spontanée, pendant le travail, d'un utérus non cicatriciel sous analgésie péridurale : à propos d'un cas. J Gynecol Obstet Biol Reprod 1995;24 (5) :557-560

6. Bevan J.R., Marley N.J.E., Ozumba E.N. Uterine rupture, placenta percreta and curettage in early pregnancy. Case report. Br J obstet Gynecol 1985;92(6):642-645

7. Tannous W, Hamou J, Henry-Suchet J., Achard B., Leiaidier C., Belaisch-Allart J. Uterine rupture during labor following surgical hysteroscopy. Presse med 1996:25(4):159-161

8. Van Alphen M., Van Vugt J.M.G., Hummel P., Van Geijn H.P.Recurrent uterine rupture diagnosed by ultrasound. Ultrasound Obstet Gynecol 1995;5(6):419-421

9. Pan H.S., Huang L.W., Hwang J.L., Lee C.Y., Tsai Y.L., Cheng W.C. Uterine rupture in an unscarred uterus. After application of fundal pressure. A case report. J Reprod Med 2002;47(12): 1044-1046

10. Yeou-Lih Wang, Tsung - Hsien SU. Obstetric uterine rupture of the unscarred uterus: a twentyyear clinical analysis. Gynecol Obstet Invest 2006; 62(3):131-135 